\title{
Flipping the class - University chemistry students' experiences from a new teaching and learning approach
}

\author{
${ }^{1}$ Department of Science and Mathematics Education, Umeå University, Umeå, Sweden, E-mail: Karolina.broman@umu.se \\ ${ }^{2}$ Department of Chemistry, Umeå University, Umeå, Sweden
}

\begin{abstract}
:
University chemistry courses have for a long time had a similar conventional approach to teaching, with chemistry professors lecturing in a traditional manner. Today, flipped learning approaches have found their ways into higher education with positive results. In particular, US innovations in this area have made positive impressions on Swedish university chemistry educators, resulting in an interest and curiosity in integrating a flipped model into the course curricula. The rationale behind flipped learning is to incorporate an active learning approach into lecture, thereby increasing both student engagement and learning outcomes. In this paper, an implementation project where an organic chemistry course has changed focus from traditional teaching to flipped learning, will be presented. The focus in this mixed-methods study will be on students' cognitive and affective responses when meeting a new teaching and learning approach. Through following a project where a conventional approach to an organic chemistry course is changed into a more student-active focus, we elaborate on implications for course development of chemistry curricula.
\end{abstract}

Keywords: higher education, organic chemistry, peer learning

DOI: 10.1515/cti-2018-0004

\section{Introduction}

Flipped learning approaches have emerged since the beginning of the $21^{\text {st }}$ century to make students' learning environments more active and thereby improve learning outcomes and student engagement (Seery, 2015). These new approaches have been applied to different subjects, and at different educational levels. Higher education studies, however, have focused STEM-subjects, i.e. science, technology, engineering, and mathematics (Lundin, Bergviken Rensfeldt, Hillman, Lantz-Andersson, and Peterson 2018). Within chemistry, several US studies present quantitative projects that involve large student groups, from hundreds to even thousands of students (e.g. Eichler \& Peeples, 2016; Siebert, Daniel, \& Hight, 2017), with some research centering on smaller groups (e.g. Christiansen, 2014; Christiansen, Lambert, Dadelson, Dupree, \& Kingsford, 2017). For this longitudinal project, we studied a Swedish organic chemistry university course, both quantitatively and qualitatively, over two years, during which we contrasted a more traditional teaching method with a new pedagogical approach founded on educational research objectives. The starting point was to emanate from existing learning theories by using competence from a chemistry education researcher (first author) and a chemistry lecturer (second author), and through this, develop and explore this new approach. The university chemistry department sought to enhance the curriculum to improve students' learning outcomes and increase students' positive engagement. Like similar US versions (Siebert et al., 2017), the organic course is perceived as being difficult and, according to previous course evaluations, the organic curriculum has been described as having a bad quality in general. Therefore, a change was requested both from students and the department.

\section{Background}

Flipped learning is a teaching and learning approach where activities in class and at home are shifted relative to traditional teaching, i.e. lectures are moved from university lecture halls to something students do at home, and problem solving and "homework" are done in class (Christiansen, 2014; Reidsema, Kavanagh, Hadgraft, 
\& Smith, 2017). As Pienta expresses, "lecturing in general or organic chemistry is easy. Doing the things to make sure everyone in one's class learns is far more challenging" (Pienta, 2016, p. 1). Flipping a classroom does not involve a fixed and regulated methodology with explicit rules, and several different approaches have been presented in previous research (e.g. Christiansen et al., 2017; Eichler \& Peeples, 2016; Mooring, Mitchell, \& Burrows, 2016). However, three main ideas portraying flipped learning are stated by Schnell and Mazur (2015): (1) to achieve deeper learning, prior knowledge is required, (2) engagement helps students learn better, and (3) flipped classrooms influence students' learning outside the course frame, thereby affecting their future self-regulated learning. The importance of prior knowledge as a foundation for higher-order thinking has been highlighted for many years by several scholars (cf., Ausubel, Novak, \& Hanesian, 1968; Zohar, 2004), and within the flipped learning approach, this is often achieved through online lectures that students watch before coming to class.

In this project, students' prior knowledge using online lectures and quizzes is explored from different perspectives through a mixed-methods setup. Nevertheless, flipped classroom approaches do not depend on the online technology; the pedagogy or philosophy instead focuses generally on a new mindset, where active learning and the active learner are emphasised, rather than teaching and the teacher (Schnell \& Mazur, 2015; Seery, 2015). Although popular, flipped learning has been questioned in a study investigating 10 flipped courses from the health domain (McNally et al., 2017), mainly because the new approach has not been thoroughly studied from a scientific point-of-view. This lack of anchoring in learning theories when applying flipped approaches is something Lundin and colleagues Lundin et al. (2018) also emphasise. According to McNally et al.'s study, the students fall into one of two clusters: Flip endorsers and Flip resisters, but even when students find the flipped approach more difficult and resist it, both student outcomes and participation in the course can improve. To find both endorsers and resisters, we decided that a combination of quantitative and qualitative data was preferred, together with both cognitive and affective learning theories.

Flipped approaches are, in a recent systematic review of 530 publications (Lundin et al., 2018), presented as a substantially growing research area, but still a fragmented and scattered field, and wherein educational theories often are lacking as foundation for the studies. When grounded in learning theories, flipped learning approaches can emanate from several different theoretical frameworks; Seery (2015) presents connections to constructivism, cognitive load theory, or different motivation theories (e.g. self-determination theory). In this longitudinal project, students' use of the pre-lecture assets, that is, online lectures and quizzes, relates to the constructivism paradigm, whereas students' collaboration in the group work in class and peer instruction relates to a more socio-cultural paradigm (Mooring et al., 2016). In this paper, we study and analyse students' collaboration using the framework of added value in communities and networks from Wenger, Trayner, and de Laat (2011). Moreover, we also explore students' perceived interest using interest frameworks from Krapp and colleagues (2011).

Perceived interest and value are therefore, in this paper, two aspects considered important if students are to use the flipped learning material. Interest is, in previous research, described as a multidimensional construct, and it can be both analysed and operationalised at different levels of generality, and under consideration of different structural components of the interest concept (e.g. Dierks, Höffler, \& Parchmann, 2014; Häussler \& Hoffman, 2000; Potvin \& Hasni, 2014). From early work by Renninger, Hidi, and Krapp (1992), as well as Krapp and Prenzel (2011), interest is subdivided into situational interest and individual interest as a means of exploring if the situation (with its external factors) and/or the individual (with his/her internal factors) influence the students' interest in organic chemistry. In another study, Häussler and Hoffman (2000) propose a distinction between content, context, and activity, where content is related to the what-question of teaching, context to the why-question, and activity to the how-question that teachers ask themselves when planning their teaching. From this, a dimension between domain and subject interest has been suggested. Krapp and Prenzel claim that "students' generalised evaluations of the 'interestingness' of school subjects are not only (or primarily) determined by the kind of knowledge they expect to acquire in the lessons (domain interest) but also by other aspects such as the expected (extrinsic) outcome of learning, the perceived difficulty or prejudices towards the 'typical' teachers of these subjects" (Krapp \& Prenzel, 2011, p. 36). From this perspective, different facets of the interest construct can be explored; for example, cognitive/epistemic (wanting to know more), emotional (enjoying), and value-related (considering to be important) aspects. In this study, the value-related aspect has been important to take into account, because there is a teaching and learning approach that is new to the students. Interest in itself is thereby not sufficient; students have to find the new approach worthwhile. Otherwise, it will probably not be used to its full potential.

Value can be studied, for example, using Wenger et al. (2011) framework for promoting and assessing value creation in communities and networks. Their definition of value creation means "the value of the learning enabled by community involvement and networking" (Wenger et al., 2011, p. 7). In flipped learning approaches, the students work together in small groups during the lessons after watching online lectures at home before coming to class. Therefore, they are involved in learning communities and network with each other. These net- 
works relate to the socio-cultural perspective of learning, where students develop their individual competence through peer interaction, by solving problems together. Value in itself is, as interest, also a broad construct with a long history of research. Eccles and colleagues (e.g. 1983) connect values with expectancies and discuss how students' behaviour is affected. When implementing a new teaching and learning approach, students' behaviour has to change. Thus, they have to use their time in different ways when taking this course, compared to others.

With an aim to explore how students use the teaching material developed for this new learning approach, the research question in this study is: How do chemistry students at the university level use different learning materials within flipped courses, and how do these learning materials influence students' affective learning (i.e., interest and value) about this approach?

\section{Method}

This study uses the format of a structure previously applied during a US flipped organic chemistry university course (Eichler \& Peeples, 2016). Flipped learning studies are uncommon in Sweden; Lundin et al. (2018) show that out of the 530 papers in their review, only 3 were published in Sweden, compared to 321 in the U.S. The published papers we have found all relate to primary or secondary level and do not focus specifically on chemistry (e.g. Hultén \& Larsson, 2018). Therefore, our study has been informed by previous flipped chemistry projects from the US, even though differences in the higher education systems are obvious.

In the pre-lesson step, online lectures were available to the students who were supposed to look them through before coming to class. After watching the lectures, short quizzes were given, which the students were asked to solve the evening before the scheduled class, at the latest. All course material was produced in English, even though most students speak Swedish as their first language. This was due to the course being open to foreign exchange students. During the first year, the teacher (second author) looked through the quiz results before class to assess students' responses and potential misconceptions. During the second year, the students discussed in small groups (3-4 students) what was unclear to them in the online lectures they had watched. Questions that still remained after holding these small-group discussions were answered in class by the teacher, which took about 15-20 min. Thereafter, the students solved problems from the course textbook in their small groups using peer instruction. If the group could not arrive at an answer, they could discuss and get feedback or leads from the teacher. This part of the lesson was often concluded by one or two questions that the students answered using their smartphones as a response system, in order to get direct feedback on their level of understanding of the subject. The last hour was devoted to more complex questions, often from previous exams. Therefore, during the scheduled lessons, in-class collaborative group learning focused on difficulties and ambiguities students had observed in their preparations. Students' work with problem solving and peer instruction was observed and explored by the first author (Schnell \& Mazur, 2015).

Several flipped learning studies have used large questionnaires to probe students' motivation (Abeysekera \& Dawson, 2015; Liu, Raker, \& Lewis, 2018). With smaller student groups, common in Sweden, large quantitative studies are problematic to realise. Therefore, a mixed-methods study was applied to investigate students' use and impressions of the learning material (i.e. perceived interest and value), as well as this new teaching and learning approach. Other advantages of a mixed-methods approach are that interviews give more in-depth information where clarifying questions can be posed, and classroom observations give the researcher a possibility to follow changes throughout the course (Cohen, Manion, \& Morrison, 2017). Three surveys with both open and closed questions were given to the students at the start, middle, and end of the course, to collect their feedback on how they used the teaching material, as well as their perception of that use. Questions on interest, value, and time used for the course were also posed. The actual use of the teaching material (the online lectures, handouts, and quizzes) was also monitored through the university's learning management system. Besides quantitative empirical data, the first author conducted student interviews after the course and classroom observations were made to evaluate the in-class group-work discussions. These semi-structured interviews (15-35 min each) were done with all students who agreed to participate in the post-survey and since $25 \%$ of all students participated in the interviews, we reached saturation in terms of observations of student views and behaviors. They were asked to further elaborate on their opinions about the course by discussing its content, context, and activities. Concrete and explicit key questions from the framework on value creation in communities and networks from Wenger et al. (2011), pp. 22-23 were used as an interview guide with the students.

A half-semester organic chemistry course was followed for 2 years (spring semester 2017 and 2018). The same course will be studied for at least two more years (2019 and 2020) to be able to explore changes and to collect longitudinal data. The Year 1 enrolment included 36 students (see Table 1). For all of these, it was their first flipped chemistry course. The teacher (second author) developed the course and produced all learning 
materials, including handouts, quizzes, and 23 online lectures, whose average lengths were approximately 30 min each. All material, the course book, the online lectures, handouts, and quizzes, were produced in English, because the course is open to foreign exchange students. All course material was available through the university's course management system, only open to students who were accepted into the course. The teacher, an organic chemistry professor, had taught this and similar courses more than 25 times prior to this occasion. We could therefore use his competence and experience in the process. The Year 2 enrolment included 35 students who were followed in the same way (see Table 1). Standard ethical considerations were made using guidelines from the Swedish Research Swedish Research Council (2017).

Table 1: Student demographic data.

\begin{tabular}{lrr}
\hline & Year 1 (2017) & Year 2 (2018) \\
\hline Students (n) & 36 & 35 \\
Male/female (n) & $19 / 17$ & $14 / 21$ \\
Survey 1 (n) & 33 & 32 \\
Survey 2 (n) & 23 & 25 \\
Survey 3 (n) & 20 & 26 \\
Interviews (n) & 7 & 11 \\
Observations (lessons) & 5 & 4 \\
\hline
\end{tabular}

\section{Results}

In general, students in both groups had a positive opinion when entering the course, with high hopes for this new approach. None of the students in the first group had prior experience with flipped learning. For Year 2, all students had previously taken a cell biology course where flipped learning had been partly applied (equivalent to $10 \%$ of that course).

On the first day of the course, students were asked to report their interest in chemistry on a six-point Likert scale, and the mean response was 5.0 or higher for both groups (see Table 2). When comparing means of students' perceived value and interest in the different aspects of flipped learning over the two years and across three surveys (pre, middle, and post), several results were nearly identical (see Table 2).

Table 2: Mean results of pre-, middle-, and post-class surveys (1-6 Likert scale).

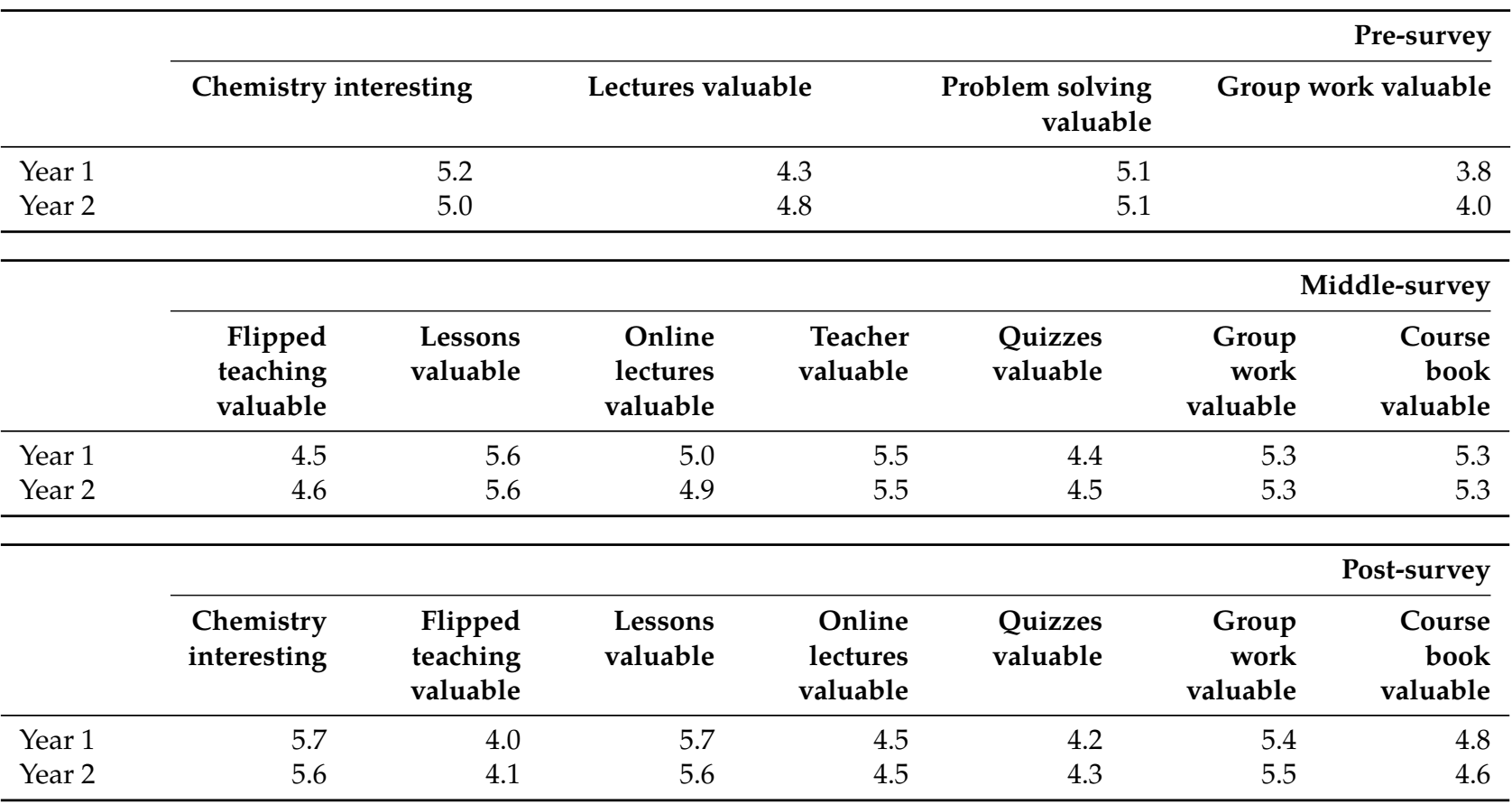


Even with a high interest when starting the course, analysing results from the pre- to post-surveys, students' general interest in chemistry increased, as well as their positive opinion of the group work. The increased general interest in chemistry was partly explained by the flipped learning approach, but also the topic of organic chemistry was rated as important for high interest. One representative comment summarised, "the first general chemistry course wasn't as relevant as this, it was so much maths and physics, here in organic chemistry, we have seen the chemistry in life and this made it interesting". In the interviews after the course, several students emphasised the positive opinion about group work. For example, one student claimed, "In school, when we had group work, it was always me who had to do everything, my classmates just chilled and made me do everything, but now here at the university, everyone has contributed and therefore it was very good to work together at the lessons". This idea of having to do 'everything' themselves in prior group experiences, was one of the most common expressions in the interviews. The lessons, in which the students solved chemistry problems in small groups while the teacher moved around in the room helping, were also perceived as valuable, with attributed value increasing over time (see Table 2).

Quizzes were used as an asset in the flipped learning approach, partly to incentivise the students to watch the online lectures before class. In the course schedule, students were supposed to watch one online lecture in the afternoon after the previous lesson, then respond to a short quiz before the next day. If the students answered the quizzes correctly, they were given a few extra credits on the final exam (a maximum of 4 points out of a total of 50 points in the final exam and 25 points to pass), thereby motivating them to both watch the lecture and respond to the short quiz tasks. Almost all students from both years answered the quizzes (this was possible to monitor through the university's learning management system), hoping to get the extra credits. As one student expressed in the interview, "I did the quiz since I thought it would be necessary to pass the final exam, but I'm not sure if it helped". After analysing both the quiz data from the learning management system, together with the exam results, the extra credits did not significantly affect most students' final grades. That is, almost all students who passed the final exam would have done so without the credits from the quizzes. When analysing students' perceived value of the quizzes, it had a lower mean than any of the other assets in the course (see Table 2).

During the interviews, students emphasised the need to keep up with the course; otherwise, attending the lessons was not meaningful. An excerpt from one of the students summarises this as follows: "Now after the course, yes, it was stressful and time-consuming, but it also made me work on with the course. From previous courses, I know, I'm often taking a week or two off in the beginning, I mean, you are tired since the last exam. Here it was obvious that you had to start directly, otherwise you couldn't do the quiz and they seemed important. Now after the exam, I'm not really sure if the quiz in itself was so valuable, but it made me study every day, something I haven't done very often". From the first author's observations of the course lessons, it was apparent that the students worked hard together, using the time to solve problems, and asked the teacher questions when needed. The teacher, who was present throughout the whole course, agreed that the students stayed active during the lessons and that almost every student came to class prepared. In the survey, students also responded to the time used, and they affirmed the flipped format to be time-consuming and even stressful, but that the flipped learning approach gave the students clear demands, and the approach explicitly showed what the students had to do every day. Through the university's learning management system, we could follow how the students actually used the online material and could correlate this with the students' own responses in the surveys.

When analysing the flipped learning approach in general, the post-surveys indicated that students valued the method, as a whole, less positively than most of its component parts (i.e. lessons, on-line lectures, group work). In the middle-survey, students stated that the flipped learning approach was perceived as valuable (mean of 4.5 and 4.6). However, this decreased by the end of the course (means 4.0 and 4.1). When asking the students to elaborate on this in the interviews, almost all of the 18 students mentioned a complication with the quizzes, blaming this as part of the reason for not seeing the full value of the flipped learning approach. This could also be seen in the surveys, where the perceived value was lower for the quizzes than for the lessons, online lectures, and group work. Students' explanations of why quizzes complicated the approach were that they were stressed by having to solve quizzes every day, and they thought the quiz results were extremely important to pass the final exam. As previously indicated, students did not get direct feedback for quiz questions or tasks that they solved correctly. This was due to a need to reuse the quiz questions in future courses. One of the students explained, "Since I didn't know if I had the correct response in the quiz, it made me stressed and also angry. I don't think I learn at all if I don't get to know if I gave the correct answer or not, how could I?". In this sense, the quizzes decreased the general perceived value of the flipped format. However, when the interviewed students were asked if they thought they would have been motivated to keep up the material, to watch the online lectures, or to go to the problem-solving lessons without the quizzes, they all agreed that the quizzes were important incentives for completing the course. 
One difference between the groups was the language used during the course. Most students at Swedish universities have Swedish as their first language. However, the studied chemistry course is available for foreign exchange students; therefore, all course material is produced in English. This is quite common for Swedish university chemistry courses. There are, for example, no university chemistry textbooks published in Swedish; therefore, students are accustomed to reading English texts and solving problems in English. Out of 32 students in Year 1, 10 were non-Swedish students, which forced the teaching and discussion language in the classroom to be English. By comparison, all students in Year 2 spoke Swedish, making this the discussion language in class, even though all course material was still in English. In the interviews, all Swedish-speaking students from Year 1 reported that it was a complicating factor for the learning process, having to discuss everything in English, despite being accustomed to English course material. This was also apparent from the observations: the discussions had a better flow when all students in a group had the same first language. In Year 2, language was never indicated as a complicating factor since all students had Swedish as their first language.

Some individual students felt more negatively toward the course than the general group. For instance, in the post-survey, students could decide for themselves if they had time for an interview. Two of the 18 interviewed students had a clearly negative opinion about flipped learning. Several aspects were mentioned as problematic. These included stress from the quizzes, as well as the online lectures being too short (30 min versus to the conventional 2-3 h) and difficult to follow, relative to standard whiteboard lectures, where the organic chemistry mechanisms "evolve" as the lecturer draws. The length of the lectures was discussed with the teacher, who claimed that he covered almost as much in $30 \mathrm{~min}$ online as in a live 2-h lecture. On the other hand, three of the interviewed students had previously taken the course using a traditional-lecture format, which they had not passed. These students were all adamant that the flipped method was better. For example, one of them stated, "this approach made me stay on top, I always knew what to do each day, and even if I understand I had an advantage from having heard words like Hofmann, Grignard and Friedel-Craft [reaction mechanism names] before, I really appreciate this kind of course".

When exploring the result of the final exams, it is difficult to compare the written course exams between different years. Nevertheless, when comparing with previous years, the teacher noted that the results after one exam and one re-exam for both flipped years were better than for the traditional-lecture years. By the end of this project, we will have exam results from 4 years, which will improve the comparisons between the conventional and flipped approach. Additionally, end-of-term course evaluations also indicated that students were generally more positive about flipped courses than the traditional-lecture courses in the past. For instance, during 2015 and 2016 (traditional format), students claimed the course to be "bad", whereas during 2017 and 2018 (flipped format), students' opinions became more positive.

To summarise the results, students found the flipped learning approach valuable and chemistry interesting after the course. The reason for finding the approach valuable was first and foremost, the students realised it made them study continually. Second, students found value in spending in-class time with the teacher in a more active way, not just listening to lectures, but instead solving problems in small groups, with help from the teacher and their peers. This confirms Wenger et al. (2011) framework on added value in communities. The quizzes seemed to yield dual consequences: the positive part being to motivate students to watch the online lectures and therefore keep up with the course, and the negative part being to cause the students more stress. One difference from the U.S. study we emanated from (Eichler \& Peeples, 2016) was language. In the U.S. study, all course material and all teaching were in English; in our project, the students have to switch between Swedish and English, possibly complicating the learning process.

\section{Discussion}

In general, students' positive opinions of the organic chemistry course and the flipped learning approach can probably be explained in several ways. Both quantitative and qualitative results indicate that the students hold a high interest in organic chemistry, both when entering and leaving the course. This is, however, a difference from years before the flipped approach was introduced: from course evaluations of the conventional approach in 2015 and 2016, students clearly held negative opinions after the course. Still, an explanation of the more positive results with the flipped approach 2017 and 2018 could be that students appreciated the course because they realised that the course had changed with intentions to improve, the so-called Hawthorne effect.

In the interviews, both situational aspects of the flipped learning approach, as well as individual personal interest in chemistry (e.g. the students had chosen university programmes with several chemistry courses), were emphasised. According to Häussler and Hoffman (2000), such interest motivates students to value the course content, context, and activities, which helps them to better grasp why chemistry is important for them in the future, and to better appreciate the activities implemented in the flipped learning approach. The result 
that different activities (e.g. problem-solving lessons with group work, and watching online lectures) were found to be more valuable than the approach as a whole, might be due to the perceived stress, caused mainly by the quizzes. The quizzes served, as planned, to motivate the students to watch the lectures and solve the quizzes, thereby being more prepared for the group discussions. However, it seems in the results that the stress experienced by the students made them value the approach less, as a whole, than its individual parts. Students who were not prepared did not come to the lessons, probably because they experienced the discussions and problem solving difficult to follow. The majority of students who actually attended the problem-solving lessons worked actively together through peer learning, with advantages of having a teacher in the classroom. From a sociocultural perspective and Wenger et al. (2011) framework of value creation, students could, through peer learning, move together towards their zone of proximal development.

Even though the approach was perceived as being somewhat stressful and difficult, flipped learning was mostly highlighted as worthwhile, due to students feeling "forced" to keep up with the studying. This fits well with McNally et al. (2017) results presenting the two types of students (i.e. Flip endorsers and Flip resisters), stating that even though students find the flipped approach more difficult, both student outcomes, as well as their participation in the course, can improve. There were several Flip endorsers during the 2 first years of our flipped course, but also a few Flip resisters; for example, the two interviewed students who had clearly negative opinions. In the future, the role of the quizzes has to be explored further to analyse if students can find them more valuable; for example, by emphasising in the beginning of the course why quizzes are a part of the approach (i.e. for external motivation), and that the bonus points for the final exam most likely do not determine if a student passes the course or not. This can hopefully decrease students' feeling of stress from the quizzes.

\section{Conclusions}

After following a university organic chemistry course during 2 years after a change from a conventional lecturebased approach into a flipped learning approach, the conclusion is that several advantages can be observed. In general, students find the new approach valuable because they are more active and use the time in groups working and discussing with the teacher. The overall interest, both individually for chemistry and situationally regarding this approach, has increased during this course's implementation. However, there are challenges to meet during the two following years of the project: for example, how to use the quizzes to make this aspect more valuable and how to work with language. Language is criticial to learning (cf., Markic \& Childs, 2016).

In this project, we contrast the new flipped learning approach with the traditional, conventional lecturebased teaching. In a Canadian computer programming course, students met these two, but also an active learning approach within the same course (Kay, MacDonald, \& DiGiuseppe, 2018). When students compared these approaches regarding teaching, social, and cognitive presence, both advantages and disadvantages were emphasised for all three approaches. Nevertheless, the students explicitly stated five desired learning characteristics: timely guidance and feedback, clarity and detail, flexibility of instruction, application of concepts, and cognitive engagement. From these results, the upcoming two years of our project, we will use these learning characteristics as a starting point to further develop the course and to make our students active and engaged in their own cognitive learning of chemistry. From Krapp and Prenzel (2011) different facets of the interest construct; cognitive/epistemic (wanting to know more), emotional (enjoying), and value-related (considering to be important) aspects, affective learning will also be analysed further to improve our university chemistry course.

\section{References}

Abeysekera, L., \& Dawson, P. (2015). Motivation and cognitive load in the flipped classroom: definition, rationale and a call for research. Higher Education Research \& Development, 34(1), 1-14.

Ausubel, D. P., Novak, J. D., \& Hanesian, H. (1968). Educational psychology: A cognitive view (2nd ed.). New York: Holt, Rinehart and Winston.

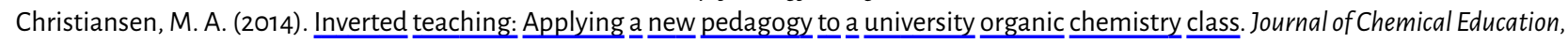
91(11), 1845-1850.

Christiansen, M. A., Lambert, A. M., Dadelson, L. S., Dupree, K. M., \& Kingsford, T. A. (2017). In-class versus at-home quizzes: Which is better? A flipped learning study in a two-site synchronously broadcast organic chemistry course. Journal of Chemical Education, 94(2), 157-163.

Cohen, L., Manion, L., \& Morrison, K. (2017). Research methods in education (8th ed.). Abingdon: Routledge.

Swedish Research Council. (2017). Cood research practice. Stockholm: Swedish Research Council.

https://www.vr.se/download/18.5639980c162791bbfe697882/1529480529472/Cood-Research-Practice_VR_2017.pdf. 
Dierks, P. O., Höffler, T. N., \& Parchmann, I. (2014). Profiling interest of students in science: Learning in school and beyond. Research in Science \& Technological Education, 32(2), 97-114.

Eccles, J. S., Adler, T. F., Futterman, R., Goff, S. B., Kaczala, C. M., Meece, J. L., \& Midgley, C. (1983). Expectancies, values, and academic behaviors. In J. T. Spence (Ed.), Achievement and achievement motivation (pp. 75-146). San Francisco: W H Freeman.

Eichler, J. F., \& Peeples, J. (2016). Flipped classroom modules for large enrollment general chemistry courses: a low barrier approach to increase active learning and improve student grades. Chemistry Education Research and Practice, 17(1), 197-208.

Häussler, P., \& Hoffman, L. (2000). A curricular frame for physics education: development, comparison with students' interests, and impact on students' achievement and self-concept. Science Education, 84, 689-705.

Hultén, M., \& Larsson, B. (2018). The flipped classroom: Primary and secondary teachers' views on an educational movement in schools in Sweden today. Scandinavian Journal of Educational Research, 62(3), 433-443.

Kay, R., MacDonald, T., \& DiCiuseppe, M. (2018). A comparison of lecture-based, active, and flipped classroom teaching approaches in higher education. Journal of Computing in Higher Education. doi:10.1007/s12528-018-9197-x.

Krapp, A., \& Prenzel, M. (2011). Research on interest in science: Theories, methods, and findings. International Journal of Science Education, 33(1), 27-50.

Liu, Y., Raker, J. R., \& Lewis, J. E. (2018). Evaluating student motivation in organic chemistry: moving from a lecture-based to a proach with peer team learning. Chemistry Education Research and Practice, 19, 251-264.

Lundin, M., Bergviken Rensfeldt, A., Hillman, T., Lantz-Andersson, A., \& Peterson, L. (2018). Higher education dominance and siloed knowledge: a systematic review of flipped classroom research. International Journal of Educational Technology in Higher Education, 15(20). doi:10.1186/s41239-018-0101-6.

Markic, S., \& Childs, P. E. (2016). Language and the teaching and learning of chemistry. Chemistry Education Research and Practice, 17, 434-438.

McNally, B., Chipperfield, J., Dorsett, P., Del Fabbro, L., Frommolt, V., Goetz, S., .... Rung, A. (2017). Flipped classroom experiences: Student preferences and flip strategy in a higher education context. Higher Education, 73, 281-298.

Mooring, S. R., Mitchell, C. E., \& Burrows, N. L. (2016). Evaluation of a flipped, large-enrollment organic chemistry course on student attitude and achievement. Journal of Chemical Education, 93(12), 1972-1983.

Pienta, N. J. (2016). A “Flipped Classroom" reality check. Journal of Chemical Education, 91(1), 1-2.

Potvin, P., \& Hasni, A. (2014). Interest, motivation and attitude towards science and technology at K-12 levels: A systematic review of 12 years of educational research. Studies in Science Education, 50(1), 85-129.

Reidsema, C., Kavanagh, L., Hadgraft, R., \& Smith, N. (2017). The flipped classroom. Practice and practices in higher education. Singapore: Springer. Renninger, K. A., Hidi, S., \& Krapp, A. (1992). The role of interest in learning and development. Hillsdale, N]: Erlbaum.

Schnell, J., \& Mazur, E. (2015). Flipping the chemistry classroom with peer instruction. In ]. Garcia-Martinez \& E. Serrano-Torregrosa (Eds.), Chemistry education: Best practices, innovative strategies and new technologies. Weinheim: Wiley-VCH.

Seery, M. K. (2015). Flipped learning in higher education chemistry: emerging trends and potential directions. Chemistry Education Research and Practice, 16(4), 758-768.

Siebert, M. R., Daniel, T. E., \& Hight, B. D. (2017). Boot camp to improve student perception and performance in sophomore organic chemistry? Hoorah! Journal of Chemical Education, 94, 1860-1865.

Wenger, E., Trayner, B., \& de Laat, M. (2011). Promoting and assessing value creation in communities and networks: A conceptual framework. Heerlen: Ruud de Moor Centrum, Open Universiteit. http://wenger-trayner.com/wp-content/uploads/2011/12/11-04Wenger_Trayner_DeLaat_Value_creation.pdf.

Zohar, A. (2004). Higher order thinking in science classrooms: students' learning and teachers' professional development (Vol. 22). Dordrecht: Kluwer Academic Publishers. 